\title{
PENGARUH LINGKUNGAN KERJA, BUDAYA ORGANISASI, PENGEMBANGAN KARYAWAN DAN KEPUASAN KERJA TERHADAP RETENSI KARYAWAN GENERASI Y DI PT PAMAPERSADA NUSANTARA
}

\author{
Husain Nurisman \\ Sekolah Tinggi Ilmu Ekonomi Rawamangun \\ husainnurisman@yahoo.com
}

\begin{abstract}
The aim of this study to investigate the impact of Work Enviroment, Organization Culture, Employee Development, Job Satisfaction to Gen Y Employee Retention using Structure Equation.

The data is obtained from 225 Gen Y employees from PT Pamapersada Nusantara. The responden ware chosen by Proportionate Stratified Sampling Technique. The data was collected with questionaire and analysis with Structure Equation Modeling (SEM).

Result of this study is there is a significant impact of Work Enviroment, Organization Culture, Employee Development to Job Satisfaction and there is no significant impact of Work Enviroment, Organization Culture, Employee Development, to Employee Retention also there is indirect effect of Organizational Culture and Employee Development to Employee Retention through Job Satisfaction.
\end{abstract}

Keyword : Work Enviroment, Organization Culture, Employee Development, Job Satisfaction, Employee Retention, Gen Y

\section{PENDAHULUAN}

Sebuah fakta yang menarik dalam perkembangan dunia Human Capital saat ini adalah kemunculan Generasi Y yang mulai mengisi posisi penting dibeberapa perusahaan di Indonesia. Dalam buku Generations: The History of America's Future 1584 to 2069, William Strauss dan Neil Howe menulis tentang perkembangan generasi di Amerika Serikat, salah satunya adalah Generasi Millenium atau Generasi Y (kompasiana, 2014).Generasi (Generation) dapat didefinisikan sebagai kumpulan orang-orang yang dibagi berdasarkan umur, lokasi tempat tinggal, dan tahapan suatu peristiwa kehidupan yang dilaluinya(Kian, 2013).Group generasi sering disebut kelompok yang mana anggotanya saling berhubungan satu dengan yang lainnya melalui pengalaman hidup selama bertahun-tahun. Menurut sosiolog, setiap kelompok umur tersebut dipengaruhi oleh generational markers (penanda generasi), artinya anggota kelompok tersebut dipengaruhi oleh suatu peristiwa yang berdampak pada kelompok generasi tersebut. Pengalaman hidup dalam setiap kelompok generasi akan memunculkan karakteristik, aspirasi dan harapan tersendiri.

Menurut Credit Union Magazine (2006) Generasi Y mempunyai 5 karakteristik yaitu berorentasi pada tujuan (are goal orented), mempunyai harapan yang tinggi pada pemberi kerja (have high expectation of their employeer), mengambil manfaat dari pemberi kerja (reap their employeer's benefit), cerdas secara teknologi (are technologically savvy) dan yang terakhir menginginkan pekerjaan yang flexible (want job flexibility).

Hay Recruitment menemukan bahwa generasi Y tidak menyukai berkarir dari bawah, mereka lebih menyukai tantangan langsung, pengakuan dan penghargaan dari perusahaan (Dhevabanchachai, 2013). Perusahaan yang akan dipilih oleh generasi ini adalah 
perusahaan yang mempunyai kejelasan pekerjaan dan perencanaan karir (career-path panning) sehingga mereka memiliki tujuan untuk mencapainya. Selain itu mereka hanya memilih perusahaan yang mempunyai reputasi yang baik dan identitas merek yang jelas. Generasi ini juga menginginkan tantangan secara intelektual (inteletual challenge) dan mereka menginginkan keberhasilan dan membuat suatu perbedaan. Sebagai tambahan mereka menyukai kesempatan untuk berpergian (traveling), training dan pengembangan serta terlibat dalam kegiatan sosial. Kondisi lingkungan yang mereka harapkan adalah: pertama mereka berharap memperoleh hasil yang cepat dan merasa frustasi dengan teknologi atau alur komunikasi yang lambat, untuk mengikat mereka perusahaan perlu memastikan bahwa teknologi yang ada selalu up to date. Kedua, mereka mengharapkan adanya fleksibelitas dalam hal jam kerja seperti bekerja paruh waktu.

PT. Pamapersada Nusantara (PAMA) adalah perusahaan kontraktor pertambangan yang sedang tumbuh berkembang. Pertumbuhan perusahaan ditandai dengan jumlah karyawan yang semakin besar yaitu sebesar 19,896 orang di tahun 2013, bertambah $250 \%$ dibanding tahun 2005 sebesar 5,667 orang.Kondisi perusahaan yang mempunyai area kerja di kabupaten-kabupaten yang jauh dari jangkauan perkotaan (remote area) dan adanya keterbatasan kondisi dalam akses komunikasi, sosialisasi dan lain sebagainya menyebabkan tingginya tingkat karyawan keluar.

Karyawan generasi Y ternyata memberikan kontribusi yang cukup besar dalam hal tingkat turnover, hal ini dapat dilihat dari total 89 karyawan staff yang keluar terdapat 60 orang atau $67,42 \%$ karyawan bergenerasi Y yang keluar pada tahun 2010 . Begitu pun untuk tahun 2011 terdapat 74,11\% ; tahun 2012 terdapat 76,92\% dan tahun 2013 terdapat 86,96\% karyawan bergenerasi $\mathrm{Y}$ yang keluar.

Selain itu berdasarkan Employee Engagement Survey (EES) pada tahun 2012 memperoleh hasil adanya karyawan yang merasa tidak puas terhadap kepemimpinan, pengembangan karyawan dan komunikasiyang ada diperusahaan saat ini. Kepemimpinan disini adalah keadilan atasan dalam memberikan penilaian kinerja, keterbukaan atasan terhadap idea yang ada, respon atasan terhadap persoalan yang terjadi pengakuan atau pujian terhadap kinerja karyawan dan yang terakhir adalah umpan balik yang diberikan atasan pada karyawan. Pengembangan karyawan adalah sistem penilaian karya yang diterapkan oleh perusahaan, upaya coaching dan counselling yang dilakukan atasan langsung dalam proses penilaian karya, kesempatan untuk mengikuti training/pelatihan yang sesuai untuk kebutuhan pekerjaan dan peluang untuk belajar hal-hal baru, sedangkan yang dimaksud dengan komunikasi disini adalah tanggapan atau respon manajemen terhadap ide karyawan, saluran atau media komunikasi yang digunakan oleh perusahaan untuk menyampaikan kebijakan perusahaan atau peraturan-peraturan baru dan kejelasan isi dari peraturan-peraturan baru (yang terkait dengan kesejahteraan, kondisi bisnis, dll).

Retensi karyawan (employee retention) merupakan suatu cara yang dilakukan oleh perusahaan agar dapat mempertahankan karyawannya agar tidak keluar dari perusahaan. Para pemimpin perusahaan harus memahami bahwa mereka mempunyai peranan penting dalam rangka mempertahankan karyawan. Menurut Deconzo dan Robbins (2010) bahwa $75 \%$ alasan karyawan keluar berada dalam kendali para manajer yaitu bagaimana mereka jujur terhadap karyawannya, memberikan pekerjaan yang menantang dan adanya pengakuaan atas prestasi yang telah mereka lakukan. Sehingga program retensi karyawan itu sangatlah penting dalam hal mengelola tingkat turnover karyawan di suatu organisasi.

Berdasarkan hal tersebut maka peneltian ini dilakukan untuk mengetahui (1)Apakah ada pengaruh positif Lingkungan Kerja, Budaya Organisasi dan Pengembangan Karyawan terhadap Kepuasan Kerja ? (2) Apakah ada pengaruh positif Lingkungan Kerja, Budaya Organisasi, dan Pengembangan Karyawan terhadap Retensi Karyawan ?(3) Apakah ada pengaruh positif Kepuasan Kerja terhadap Retensi Karyawan ?(4) Apakah ada pengaruh tidak langsung Lingkungan Kerja terhadap Retensi Karyawan melalui Kepuasan Kerja ? (5) Apakah ada pengaruh tidak langsung Budaya Organisasi terhadap Retensi Karyawan 
melalui Kepuasan Kerja ? (6) Apakah ada pengaruh tidak langsung Pengembangan Karyawan terhadap Retensi Karyawan melalui Kepuasan Kerja ?

\subsection{Model Penelitian dan Hipotesis}

Model penelitian dan hipotesis pada penelitian ini adalah sebagai berikut :

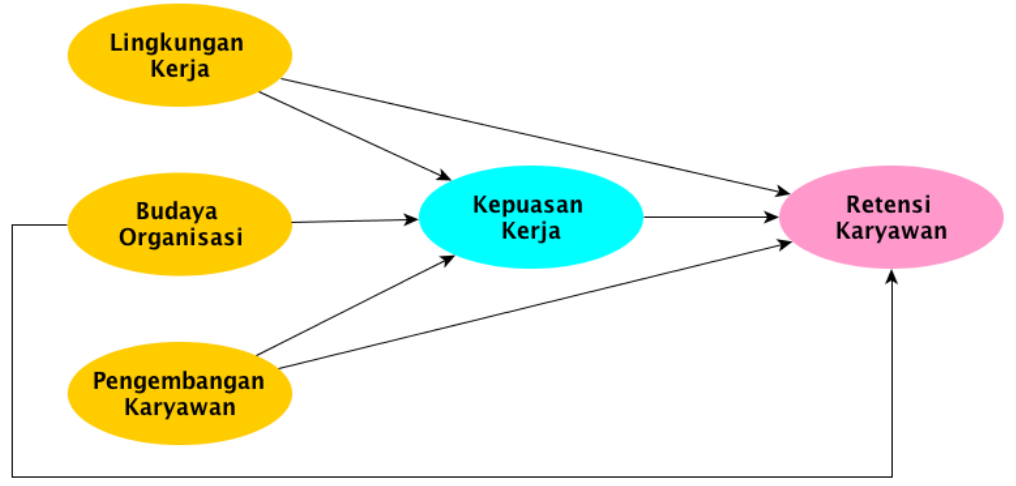

Gambar 1. Model Penelitian

$K K=\gamma_{11} L K+\gamma_{12} B O+\gamma_{13} P K+\zeta_{1}$

$R K=\gamma_{21} L K+\gamma_{22} B O+\gamma_{23} P K+\beta_{21} K K+\zeta_{2}$

Keterangan :

KK $=$ Kepuasan Kerja

RK $=$ Retensi Karyawan

LK = Lingkungan Kerja

$\mathrm{BO}=$ Budaya Organisasi

$\mathrm{PK}=$ Pengembangan Karyawan

Hipotesis Penelitian :

$\mathrm{H}_{1} \quad$ : Lingkungan Kerja, Budaya Organisasi dan Pengembangan karyawan berpengaruh positif terhadap Kepuasan Kerja.

$\mathrm{H}_{2} \quad$ : Lingkungan kerja, Budaya Organisasi dan Pengembangan Karyawan berpengaruh positif terhadap Retensi Karyawan.

$\mathrm{H}_{3} \quad$ : Kepuasan Kerja berpengaruh positif terhadap Retensi Karyawan.

$\mathrm{H}_{4} \quad$ : Lingkungan Kerja berpengaruh tidak langsung terhadap Retensi

Karyawan melalui Kepuasan Kerja.

$\mathrm{H}_{5} \quad$ : Budaya Organisasi berpengaruh tidak langsung terhadap Retensi Karyawan melalui Kepuasan Kerja.

$\mathrm{H}_{6} \quad$ : Pengembangan Karyawan berpengaruh tidak langsung terhadap Retensi

Karyawan melalui Kepuasan Kerja.

\section{KAJIAN LITERATUR}

\subsection{Lingkungan Kerja}

Menurut Munro dalam Pavee (2004) lingkungan kerja didefinisikan sebagai pekerjaan dan tempat kerja yang berpengaruh pada pekerja itu sendiri pada waktu melakukan pekerjaannya. Aspek lingkungan kerja disini termasuk hubungan antara atasan dan rekan sekerja, kesetaraan dan keadilan, kecocokan dalam bekerja dan pengendalian pekerjaan secara personal. 
Sebuah organisasi perlu menciptakan lingkungan kerja yang "unik" sehingga dapat digunakan sebagai "selling point" untuk mendapatkan karyawan baru. Dari penelitian yang dilakukan diketahui bahwa generasi $\mathrm{X}$ dan $\mathrm{Y}$ mencari lingkungan kerja yang menyenangkan dan kreatif yang dapat diterjemahkan sebagai lingkungan yang mempunyai ruang terbuka, lingkungan yang dapat dipercaya dan organisasi yang dapat memberikan nilai hiburan (contoh : adanya fasilitas olahraga, permainan, hiburan, dll). Selain itu qualitas lingkungan kerja dapat mempengaruhi moral pekerja, produktifitas dan turnover. Dengan kata lain lingkungan kerja dapat berpengaruh terhadap tingkah laku karyawan dalam bekerja, produktifitas pekerja dan memberikan kepuasan dalam bekerja.Karakteristik lingkungan kerja yang dapat memperngaruhi kepuasan kerja adalah :

1. Keterbukaan komunikasi yaitu bagaimana perusahaan melakukan komunikasi terhadap Visi dan Misinya sehingga karyawan dapat mendukung tercapainya Visi dan Misi tersebut.

2. Keseimbangan hidup yaitu adanya keseimbangan antara urusan perusahaan dan urusan pribadi atau keluarga.

3. Konsistensi yaitu menciptakan kondisi rasa tanggung jawab atasan terhadap permasalah-permasalahan yang sedang dihadapi.

\subsection{Budaya Organisasi.}

Menurut Robbin (2013), budaya organisasi adalah suatu persepsi bersama yang dianut oleh anggota-anggota yang berada didalam organisasi yang merupakan pembeda dengan organisasi lain. Budaya organisasi merupakan hasil dari budaya yang dominan dalam suatu organisasi yang dinyatakan melalui nilai-nilai inti (Core Values) dari mayoritas anggota yang ada diorganisasi tersebut. Dengan budaya yang kuat (Strong Culture), nilai-nilai inti organisasi akan selalu secara intensif disosialisasikan pada seluruh karyawannya, sehingga semakin besar karyawan menerima nilai-nilai inti yang ada maka akan semakin besar pula komitmen terhadap organisasi.Dengan budaya yang kuat akan mempengaruhi perilaku karyawan yang ada dan dapat menurunkan tingkat turnover karena budaya yang kuat akan membangun keterikatan antar anggota, loyalitas terhadap organisasi dan membangun komitmen organisasi (Organizational Commitment).

Mencocokan karyawan generasi $\mathrm{Y}$ dengan pemberi kerja merupakan hal yang mendasar dalam membangun hubungan jangka panjang yang sukses. Generasi Y secara khusus tertarik terhadap perusahaan yang mempunyai budaya dan etika sosial yang kuat. Agar perusahaan menarik bagi generasi Y maka perusahaan mempunyai nilai-nilai dan perilaku yang jelas (Weyland, 2011), sehingga untuk meningkatkan kepuasan kerja maka perusahaan perlu memiliki nilai-nilai inti yang telah tersosialisasi, dilaksanakan dan dipahami oleh karyawan nilai-nilai yang kerkandung didalamnya.

\subsection{Pengembangan Karyawan.}

Pengembangan karyawan (employee development) adalah kombinasi pendidikan formal dan pengalaman kerja, hubungan antar karyawan dan penilaian kepribadian (assessment of personality) dan kemampuan untuk membantu mempersiapkan karirnya dimasa yang akan datang. Dari definisi tersebut dapat dikatakan bahwa yang dimaksudkan dengan pengembangan karyawan adalah pelatihan (training), pengembangan (development) dan manajemen karir (career management). Dalam literatur lain (Mejia, 2012), yang dimaksud dengan pengembangan karyawan adalah penilaian dan pengelolaan kinerja (appraising and managing performance), Pelatihan dan Pengembangan (training and development) dan pengembangan karir (developing career).

\section{Penilaian dan pengelolaan kinerja (appraising and managing} performance).

Pada dasarnya perusahaan melakukan penilaian mempunyai tujuan hanya sebagai administraitif dan atau digunakan sebagai alat untuk menentukan pengembangan (development) karyawan. Penilaian kinerja 
(performance appraisal) hanya digunakan sebagai data administratif sebagai dasar pengambilan keputusan dalam hal kondisi kerja karyawan termasuk promosi (promotion), pemutusan hubungan kerja (termination) dan pemberian penghargaan (reward). Penilaian kinerja digunakan dalam pengembangan untuk meningkatkan kinerja karyawan dan memperkuat keahlian (skill) karyawan, termasuk didalamnya proses umpan balik (feedback) dan konseling karyawan.

\section{Pelatihan dan pengembangan (training and development).}

Yang membedakan antara pelatihan dan pengembangan adalah pelatihan (training) merupakan proses pembelajaran yang berhubungan dengan pekerjaan saat ini dan sangat dibutuhkan untuk mendukung pekerjaan karyawan sedangkan pengembangan (development) merupakan proses pembelajaran yang tidak terkait langsung dengan pekerjaan saat ini karena fokusnya adalah mempersiapkan karyawan untuk karir yang akan datang. Dalam melakukan pelatihan perlu dipastikan bahwa pelatihan yang dilakukan dapat secara langsung meningkatkan kinerja karyawan.

\section{Pengembangan karir (Career Development).}

Pengembangan karir berbeda dengan pelatihan. Pengembangan karir mempunyai fokus yang lebih luas, jangka waktu yang lebih lama dan ruang lingkup yang lebih luas. Sasaran pelatihan adalah peningkatan kinerja karyawan pada saat itu sedangkan sasaran pengembangan karir adalah memperkaya dan meningkatkan kemampuan karyawan.

\subsection{Kepuasan Kerja.}

Kepuasan kerja adalah kumpulan dari berbagai macam perasaan dan kepercayaan orang terhadap pekerjaannya pada saat itu.Kepuasan kerja merupakan hal yang sangat penting sehingga dapat berpengaruh terhadap perilaku karyawan di perusahaan tersebut yang akhirnya dapat menyebabkan tingkat karyawan keluar yang tinggi. Pada dasarnya faktor-faktor yang mempengaruhi kepuasan kerja terdiri dari 4 faktor (George, 2012)yaitu

- Kepribadian (personality), merupakan suatu sifat dasar seseorang terhadap perasaan, pemikiran dan bertingkah laku, sifat-sifat tersebut merupakan penentu bagaimana orang berfikir dan merasakan terhadap pekerjaannya atau terhadap kepuasan kerjanya. Sehingga dapat dikatakan bahwa kepuasan kerja dapat ditentukan oleh kepribadian karyawannya yang mana hal tersebut tidak dapat dirubah dengan dengan cepat sehingga dibutuhkan peran serta atasan atau manager dalam mempengaruhinya.

- Nilai-Nilai (Values), Values mempunyai pengaruh terhadap kepuasan kerja sebab values mencerminkan keyakinan karyawan untuk mencapai hasil dari pekerjaannya dan bagaimana karyawan harus bertingkah laku dalam bekerja.

- Situasi Kerja (The Work Situation),merupakan sumber yang terpenting untuk mencapai Kepuasan Kerja. Situasi kerja dapat diartikan sebagai bagaimana seseorang mengerjakan tugasnya (ketertarikan akan pekerjaan atau bosan terhadap pekerjaan), bagaimana mereka berinteraksi dengan customer, bawahan atau atasan, lingkungan sekitar tempat orang tersebut bekerja (kebisingan, keramaian dan suhu), bagaimana organisasi memperlakukan karyawannya dalam hal keamanan dalam bekerja (job security) yg diberikan, keadilan dalam pemberian gaji dan benefit. 
- Pengaruh Sosial (social influence), faktor terakhir yang berpengaruh terhadap kepuasan kerja adalah pengaruh sosial berupa pengaruh individu atau kelompok terhadap sikap dan perilaku seseorang. Rekan kerja, kelompok tempat orang tersebut berasal, budaya di tempat mereka tumbuh besar dan tempat mereka hidup merupakan hal-hal yang berpengaruh terhadap tingkatan kepuasan kerja karyawan.

\subsection{Retensi Karyawan.}

Retensi karyawan adalah kemampuan organisasi untuk mempertahankan karyawannya. Salah satu cara untuk mempertahankan karyawan adalah dengan cara melakukan pengelolaan tingkat turnover karyawan. Turnoveradalah tingkat atau jumlah dimana karyawan meninggalkan suatu perusahaan. Tingkat ini mencerminkan karyawan yang meninggalkan perusahaan karena mengundurkan diri atau pensiun tetapi tidak termasuk untuk karyawan yang meninggalkan perusahaan disebabkan oleh performance yang buruk, cacat atau adanya perampingan perusahaan (corporate downsizings)(Dessler, 2013). Dengan kata lain untuk mempertahankan karyawan (retensi karyawan) agar tidak keluar maka perusahaan perlu melakukan program program yang dapat menurunkan tingkat turnover karyawan. Robert L Mathis dan John H Jackson (Mathis, 2010)menuliskan bahwa mempertahankan karyawan yang baik merupakan tantangan bagi semua organisasi dan merupakan hal yang sulit karena adanya perubahan pasar tenaga kerja. Untuk mempertahankan karyawan yang dapat dilakukan adalah :

1. Kompensasi dan benefits. Perusahaan perlu memastikan bahwa kompensasi dan benefit yang diberikan perusahaan telah kompetitif dan dapat mencegah karyawan untuk keluar.

2. Hubungan Kerja yaitu pengawasan dan dukungan manajemen dan hubungan antar rekan sekerja.

3. Implementasi kebijakan perusahaan yaitu memastikan bahwa perusahaan telah menerapkan aturan secara adil ke seluruh karyawan.

\section{METODOLOGI PENELITIAN}

\subsection{Sampel}

Sample penelitian terdiri dari karyawan generasi Y di perusahaan PAMA yang tersebar di 15 area kerja di Kalimantan (14 lokasi) dan Sumatera (1 lokasi), dengan total responden sebanyak 225 karyawan Gen Y.

\subsection{Instrumen}

Pengambilan data dilakukan dengan menggunakan metode survey. Kuesioner menggunakan skala likert dari 1 (sangat tidak setuju) sampai dengan 5 (sangat setuju). kuesioner terbagi atas 5 bagian yaitu variabel Lingkungan Kerja terdiri dari 14 item, variabel Budaya Organisasi terdiri dari 18 item, variabel Pengembangan Karyawan terdiri dari 13 item, variabel Kepuasan Kerja terdiri dari 21 item dan variabel Retensi Karyawan terdiri dari 16 item.

\subsection{Analisis Data}

Reliabilitas quesioner menggunakan Cronbach Alpha, Confirmatory Factor Analysis(CFA) digunakan untuk memvalidasi model penelitian. SPSS 12.0 digunakan untuk statistik diskriptif dan Hipotesis penelitian mengunakan Structure Equation modelling dengan software Lisrel 8.8.

\subsection{Validitas dan Reliabilitas}

Uji validitas yang digunakan pada penelitian ini adalah uji validitas konstrukdengan menggunakan Standard Loading Factor (SLF) dan kriteria minimal semua loading factor 
secara statistik signifikan dan sebagai batas acuan nilai loading factor adalah 0,5 dan disarankan 0,70 ( SLF > 0,5). Sedangkan uji reabilitas yang digunakan adalah reliabilitas instrumen menggunakanComposite Reability $(C R)$ dan AVE (Average Variance Extracted). Dimana nilai yang digunakan untuk menyatakan bahwa instrumen tersebut reliabel adalah minimal 0,6 dan disarankan 0,7 untuk pengukuran Construct Realibility $(\mathrm{CR}>0,7)$ dan minimal 0,5 untuk pengukuran average variance extracted (AVE $>0,5$ ). Dari hasil uji reliabilitas didapatkan hasil sebagai berikut :

Tabel 1. Hasil Uji CFA

\begin{tabular}{lcc}
\hline Variabel & CR & A VE \\
\hline Lingkungan Kerja & 0,93 & 0,518 \\
Budaya organisasi & 0,93 & 0,522 \\
$\begin{array}{l}\text { Pengembangan } \\
\text { Karyawan }\end{array}$ & 0,90 & 0,473 \\
$\quad$ Kepuasan Kerja & 0,94 & 0,458 \\
Retensi Karyawan & 0,94 & 0,557 \\
\hline
\end{tabular}

\section{HASIL PENELITIAN DAN PEMBAHASAN}

\subsection{Demografi}

Dalam penelitian ini responden berjenis kelamin laki-laki sebanyak 97,33\% dan berjenis kelamin perempuan sebanyak 2,67\%. Mayoritas responden berusia antara $24-29$ tahun sebanyak 69,33\%, sedangkan sebanyak 56,89\% menyatakan telah menikah. Responden penelitian ini diikuti oleh karyawan berstatus tetap sebanyak 95,56\% sisanya 4,44\% bersatus karyawan kontrak. Karyawan yang berpindidikan D3 sebanyak 17,33\%, S1 sebanyak $82,22 \%$ dan $\mathrm{S} 2$ sebanyak $0,44 \%$.

\subsection{Hasil Model Struktural}

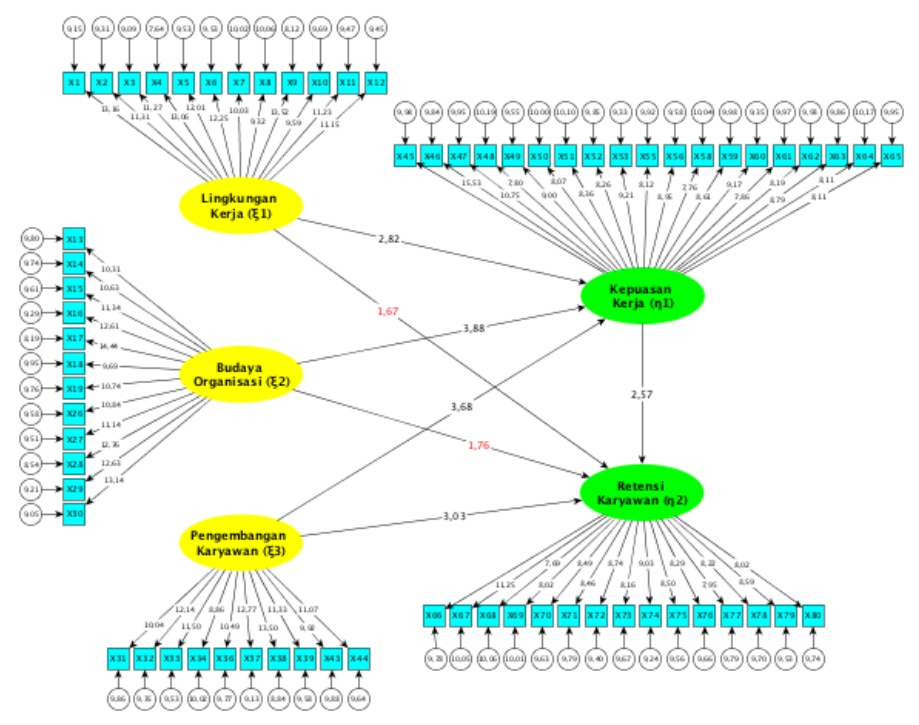

Gambar 2. Hasil Model Struktural Lisrel 8.8

Hasil model yang ditampilkan dalam gambar 1 merupakan hasil yang dikeluarkan oleh lisrel 8.88. Dari hasil pengujian yang dilakukan didapatkan 2 pengukuran GOF yang menyatakan kurang fit yaitu pada pengukuran Chi Square $(\mathrm{p}=0,00)$ dan NCP $(570,31)$, sedangkan untuk ukuran lainya dinilai Fit yaitu Normal Chi Square (1,43), RMSEA 
$(0,035)$, NFI $(0,93)$, NNFI $(0,98)$, CFI $(0,98)$, IFI $(0,98)$ dan RFI $(0,93)$. Berdasarkan hal tersebut maka model dinyatakan FIT.

Tabel 2. Hasil Uji GOF

\begin{tabular}{lccc}
\hline Ukuran GOF & Target Kecocokan & Hasil Perhitungan & Evaluasi Model \\
\hline Chi Square & $\begin{array}{c}\text { Lebih kecil lebih baik } \\
(\mathrm{P}>0,05)\end{array}$ & $\begin{array}{c}3053,48 \\
\mathrm{p}=0,00\end{array}$ & Poor Fit \\
Normal Chi & $\frac{\chi^{2}}{d f}<2$ & $\frac{3053,48}{2132}=1,43$ & Good Fit \\
Square & Nilai NCP Kecil & 570,31 & \\
NCP & $<0,05$ & 0,035 & Poor Fit \\
RMSEA & ECVI $<$ ECVI for & $13,97<20.95$ & Good Fit \\
ECVI & saturned dan ECVI for & $13.97<208,95$ & \\
& independence model & & \\
AIC dan & AIC $<$ Saturated & $3130<46805,03$ dan & \\
CAIC & AIC/CAIC & 4692 & Good Fit \\
& dan & $4075,35<4705,32$ & \\
& CAIC Independence & dan 15052,17 & \\
NFI & AIC/CAIC & & Good Fit \\
NNFI & $>0,9$ & 0,93 & Good Fit \\
CFI & $>0,9$ & 0,98 & Good Fit \\
IFI & $>0,9$ & 0,98 & Good Fit \\
RFI & $>0,9$ & 0,98 & Good Fit \\
\hline
\end{tabular}

Dari model tersebut memiliki 6 hipotesis yang diuji, dari ke 6 hipotesis yang di uji hanya ada 2 hipotesis yang ditolah yaitu hipotesis $2\left(\mathrm{H}_{2}\right)$ dan hipotesis $4\left(\mathrm{H}_{4}\right)$.Sedangkan 4 hipotesis lainnya dinyatakan diterima yaitu hipotesis $1\left(\mathrm{H}_{1}\right)$, hipotesis $3\left(\mathrm{H}_{3}\right)$, hipotesis 4 $\left(\mathrm{H}_{4}\right)$, hipotesis $5\left(\mathrm{H}_{5}\right)$ dan terakhir hipotesis $6\left(\mathrm{H}_{6}\right)$. Hal ini berarti adanya pengaruh positif antara Lingkungan Kerja, Budaya organisasi dan Pengembangan Karyawan terhadap Kepuasan Kerja serta Kepuasan Kerja berpengaruh positif terhadap Retensi Karyawan. Selain itu adanya pengaruh tidak langsung antara Budaya Organisasi dan Pengembangan Karyawan terhadap Retensi Karyawan melalui Kepuasan Kerja.

Tabel 3. Hasil Hipotesis

\begin{tabular}{|ccccc|} 
Model & Parameter & $\begin{array}{c}\text { Loading } \\
\text { Factor }\end{array}$ & $\begin{array}{c}\text { T } \\
\text { Value }\end{array}$ & Hipotesis \\
\hline $\mathbf{H}_{\mathbf{1}}$ & $\mathrm{LK} \rightarrow \mathrm{KK}$ & 0,19 & 2,88 & Diterima \\
& $\mathrm{BO} \rightarrow \mathrm{KK}$ & 0,31 & 3,88 & \\
& $\mathrm{PK} \rightarrow \mathrm{KK}$ & 0,15 & 3,68 & \\
\hline $\mathbf{H}_{\mathbf{2}}$ & $\mathrm{LK} \rightarrow \mathrm{RK}$ & 0,12 & $\mathbf{1 , 6 7}$ & Ditolak \\
& $\mathrm{BO} \rightarrow \mathrm{RK}$ & 0,15 & $\mathbf{1 , 7 6}$ & \\
& $\mathrm{PK} \rightarrow \mathrm{RK}$ & 0,28 & 3,03 & \\
& $\mathrm{KK} \rightarrow \mathrm{RK}$ & 0,23 & 2,57 & \\
& & & & \\
\hline $\mathbf{H}_{\mathbf{3}}$ & $\mathrm{KK} \rightarrow \mathrm{RK}$ & 0,23 & 2,57 & Diterima \\
\hline $\mathbf{H}_{\mathbf{4}}$ & $\mathrm{LK} \rightarrow \mathrm{KK} \rightarrow \mathrm{RK}$ & $0,19 \times 0,23=0,0437$ & Ditolak \\
\hline $\mathbf{H}_{\mathbf{5}}$ & $\mathrm{BO} \rightarrow \mathrm{KK} \rightarrow \mathrm{RK}$ & $0,31 \times 0,23=0,073$ & Diterima \\
\hline $\mathbf{H}_{\mathbf{6}}$ & $\mathrm{PK} \rightarrow \mathrm{KK} \rightarrow \mathrm{RK}$ & $0,31 \times 0,23=0,073$ & Diterima \\
\hline
\end{tabular}




\subsection{Pembahasan}

Tujuan utama penelitian ini adalah untuk mengetahui hubungan antara Lingkungan Kerja, Budaya Organisasi dan Pengembangan Karyawan, Kepuasan Kerja dan hubungan antara Lingkungan Kerja, Budaya Organisasi, Pengembangan Karyawan dan Kepuasan Kerja terhadap Retensi Karyawan.

Dari hasil penelitian ini didapatkan bahwa adanya pengaruh positif Lingkungan Kerja Budaya Organisasi dan Pengembangan Karyawan terhadap Kepuasan Kerja. Hal ini sesuai dengan penelitian Kungshuk Adhikari dan Pinak Deb (2013) yang menyatakan bahwa faktor-faktor yang berpengaruh terhadap kepuasan kerja adalah Lingkungan Kerja dan Pengembangan Karyawan (promosi dan pengawasan). Hal serupa yang disampaikan oleh Su-Chao Chang dan Ming-Shing Lee (2007) yang menyampaikan adanya hubungan antara Budaya Organisasi dan Pengembangan Karyawan (Organisasi Pembelajaran) terhadap Kepuasan Kerja.Sehingga dapat diambil kesimpulan bahwa untuk meningkatkan Kepuasan Kerja maka perusahaan perlu memastikan bahwa kondisi lingkungan kerja tempat karyawan bekerja sudah baik yaitu adanya keterbukaan komunikasi, adanya kestabilan dan keseimbangan antara bekerja dan kehidupan atau keluarga (Stabilty of Work Life) dan adanya dukungan atasan dan tanggung jawab atasan dalam pekerjaan-pekerjaan yang dilakukan. Selain itu agar perusahaan dapat menarik karyawan generasi Y maka perusahaan perlu menciptakan Budaya Organisasi yang kuat dengan cara melakukan sosialisasi dan implementasi nilai-nilai inti serta perusahaan juga perlu mempunyai sistem pengembangan karyawan yang baik dalam hal penilaian dan pengelolaan kinerja, pelatihan dan pengembangan dan pengembangan karir.

Dalam penelitian ini juga didapatkan bahwa adanya hubungan tidak langsung antara Budaya Organisasi, Pengembangan Karyawan terhadap Retensi Karyawan melalui Kepuasan Kerja, hal ini berarti untuk meningkatkan Retensi Karyawan maka perlu terlebih dahulu perlu adanya Kepuasan Karyawan dalam hal budaya organisasi yaitu dengan adanya nilai-nilai inti yang telah terimplementasikan dengan baik dan adanya kejelasan dalam pengembangan karyawan.

\section{SIMPULAN DAN SARAN}

Penelitian ini sangat penting sebagai informasi bagi perusahaan untuk mempertahankan karyawannya agar tidak keluar. Dengan penelitian ini maka perusahaan perlu melakukan langkah-langkah untuk dapat mempertahankan karyawannya diantaranya adalah :

1. Peningkatan kualitas keseimbangan hidup bagi karyawan, sehingga adanya keseimbangan antara bekerja dan keluarga. Peningkatan kualitas keseimbangan hidup ini dapat dilakukan dengan cara membuat fleksibilitas dalam jam kerja yang ada dan memberikan kesempatan untuk bersama keluarga lebih banyak.

2. Atasan lebih terlibat dan bertangung jawab dalam pekerjaan yang dilakukan oleh karyawan (bawahannya) dan juga lebih banyak menyediakan waktu untuk berdiskusi dengan karyawannya.

3. Perusahaan secara terus menerus mengkampanyekan nilai-nilai yang ada di perusahaan (Nilai Inti), dimulai dari program pengenalan karyawan baru sampai dengan pengayaan (refresh) program disetiap kesempatan yang ada.

4. Perusahaan perlu memberikan target yang menantang dan memberikan penghargaan bagi karyawan generasi Y yang dapat mencapainya. Proses penilaian kinerja perlu dilakukan secara terbukan dan transparan.

5. Perlu adanya perancanaan karir yang jelas bagi karyawan generasi $\mathrm{Y}$ agar mereka memiliki tujuan yang jelas dalam bekerja. 
6. Melakukan peninjauan atau review kembali terhadap paket kompensasi dan benefit yang ada diperusahaan dan memastikan paket tersebut sesuai dengan yang dibutuhkan dan diharapkan oleh karyawan generasi $\mathrm{Y}$.

7. Setiap kebijakan-kebijakan perusahaan yang dibuat harus disosialisasikan ke karyawan generasi $\mathrm{Y}$, dan pastikan peraturan yang dibuat tidak memberatkan karyawan dalam melaksanakannya.

\section{DAFTAR PUSTAKA}

Adhikari, Kungshuk dan Pinak Deb, "Factor Influencing Job Satisfaction of Bank Employee”, Sumedha Journal of Management, 2013, Vol2. No2

Bakotic, Danica dan Tomislav Babic, "Relationship between Working Condition, and Job Satisfaction: The Case of Croation Shipbuilding Company", (International Journal of Business and Social Science, 2013)

Credit Union Magazine, "Understand Gen Y Employees", 2006

Chen, Tser-Yieth, Pao-Long Chang dan Ching-Wen Yeh, "A Study of Career Needs, Career Development Programs", Job Satisfaction and The Turnover Intention of R\&D Personnel" The Emerald Research, 2004.

Chang, Su-Chao dan Ming-Shing Lee, "A study on relationship among leadership, organizational culture, the operation of learning organization and employees job satisfaction", Emerald Inside, 2007, Vol 14 No 2

Chatterjee, Nandita, "A study of organisational culture and its effect on employee retention”, (ASBM Journal of Management, 2009)

Dachlan, Usman, Panduan Lengkap Struktural Equation Modeling, (Semarang : Lentera Ilmu, 2014).

Deconzo, David A dan Stephen P Robbins, Fundamental of Human Resources Management, USA, JohnWiley and Son Inc, 2010.

Dessler, Gary, Human Resource Management, Pearson, 2013.

Dermawan Wibisono, "Panduan Penyusunan Skirpsi, Tesis dan Disertasi", Andi Yogyakarta, 2013.

Dhevabanchachai, Neta-tra dan Kaewta Muangasame, "The prefered work paradigm for Generation $Y$ in hotel Industry : A case study of the international tourism and hospitally international programe", International Education Studies, Vol 6 No 10, 2013.

Dunamis Consulting,"37\% Karyawan di Indonesia adalah generasi Y, sudah siapkah Organisasi anda"; http://www.dunamis.co.id/index.php/knowledge/details/press/155, (Diakses tanggal 31 April 2014).

Elemore, Tim, Generation iY : Our Last Change to Save Their Future (USA, Growing Leaders. Inc, 2010).

Gurpreet Randhawa, "Relationship Between Job Satisfaction and Turn Over Intentions : An Empirical Analysis”, Indian Management Studies Journal, 2007.

George, Jennifer M and Gereth R Jones, Undertanding and Managing Organizational Behavior, Pearson, 2012.

Ghozali, Imam dan Fuad, Structure Equation Modeling, Theori, Konsep dan Aplikasi dengan Lisrel 9.10, (Semarang, UNDIP, 2014).

Haryono, Siswoyo , Parwoto Wardoyo, Structure Equation Modeling : untuk penelitian namagement menggunanakan AMOS 18.00, Intermedia Personalisa Utama, 2013.

Jain, Ruchi dan Surinder Kaur, "Impact of Work Environment on Job Satisfaction", International Journal of Scientific and Research Publications, 2014, Vol 4, Issue 1. 
Jean M. Inabinett dan Julie M. Ballaro, "Developing An Organization By Predicting Employee Retention By Matching Corporate Culture With Employee's Values: A Correlation Study" Organization Development Journal, 2014.

Jogiyanto, Metodologi Penelitian Business : Salah Kaprah dan Pengalaman-Pengalaman, Yogyakarta, 2010.

Employee", Sumedha Journal of Management,2013, Vol2. No2

Kompasiana," Kemunculan Generasi Y dalam Dunia Kerja : Menciptakan System Kerja dan Sistem Budaya yang Ramah terhadap Generasi $Y$ " ; http://ekonomi.kompasiana.com/manajemen/2013/12/17/kemunculan-generasi-ydalam-dunia-kerjamenciptakan-sistem-kerja-dan-sistem-budaya-yang-ramahterhadap-generasi-y-617207.html (DIakses tanggal 31 Maret 2014).

Kuncoro, Mudrajad, Metodologi Reset untuk Bisnis dan Ekonomi, Erlangga, 2013.

Kungshuk Adhikari dan Pinak Deb, "Factor Influencing Job Satisfaction of Bank.

Kwenin, Daisy Ofosuhene, "Developing An Organization By Predicting Employee Retention By Matching Corporate Culture With Employee's Values: A Correlation Study”, Global Journal of Human Resource Management, 2013, Vol.1 No.4.

Lim, Hwee Ling, Generation Y Workforce Expectation : "implications for the UAE", Abu Dhabi, The Petroleum Institute, 2012.

Lowe, Debra and Kenneth J. Lewitt and Terry Wilson, "Solution for Retaining Generaton Y Employees in the Workplace”, The Business Quarterly, 2008.

Management PPM "Mengenal Siapa itu Generasi Y?", http://manajemenppm.wordpress.com/2013/07/08/mengenal-siapa-itu-generasi-y/ (diakses 30 Maret 2014)

Mathis, Robert L dan John H Jackson, Human Resources Management, South-West Cengage Learning, 2010

Masyhudzulhak, Memahami Tulisan Ilmiah dan Metodologi Penelitian, Lembaga Pengkajian dan Pengembangan Sumber Daya, 2012

Mejia, Luis R Gomez dan David B Balkin dan Rebert L Cardy, Managing Human Resources, Pearson, 2012.

Messmer, Max, Human Resources Kit for Dummies, (Hoboken: Wiley Publising, 2007).

Miller, Paige E, "The Relationship Between Job Satisfaction and Intention To Live : A Study of Hospice Nurses in a Fot-Profit Corporation"

Noe Raymond A, John R Hollenback, Barry Gerhart dan Patrick M Wright, Fundamental of Human Resources Management, McGraw Hill, 2011.

Parvin, Mosammod Mahamuda, "Factors Affecting Employee Job Satisfaction of Pharmaceutical Sector", (Australian Journal of Business and Management Reserch,2011) Vol 1 No.9

Robbis, Stephen P, Orgaization Behavior, Pearson, 2013.

Sabri, Pirzada Sami Ullah Sabri, M Ilyas dan Zahra Amjad, "Organizational Culture and Its Impact on the Job Satisfaction of the University Teachers of Lahore", Internasional Journal of Business and Social Science, 2011, Vol 2 No 24

Sakaran, Uma dan Roger Bougie, Research Methode for Business, Wiley, 2013

Susan P Eister, "Managing Generation Y”, Ramopo College of New Jersey, 2005

Suvagondha, Pavee, "Relationships Among Creative Style Preference, Job Satisfaction, and Work Enviroment", Proquest Information and Learning Company, 2004.

Tejada, Jeffrey J dan Joyce Raymond B Punzalan, "On the Misuse of Slovin's Formula" (The Philippine Statistician, 2012) Vol. 61 No 1.

Time,"what gen $Y$ really wants http://content.time.com/time/magazine/article/0,9171,1640395,00.html (diakses tanggal 24 sept 2014).

UNJSPS, "Traditionalists, Baby Boomers, Generation X, Generation Y (and Generation Z) Working Together"

http://www.un.org/staffdevelopment/pdf/Designing\%20Recruitment,\%20Selection 
\%20\&\%20Talent\%20Management\%20Model\%20tailored\%20to\%20meet\%20UNJ SPF's\%20Business\%20Development\%20Needs.pdf (Diakses tanggal 31 Maret 2014).

Wan, Tan Shen,Wan Fauziah Wan Yusoff dan Sivan Rajan, "Relationship between Motovation and Citizenship Performance among Generation X and Generation Y", International Journal of Research in Business and Social Sciences, 2013, Vol 12 No 1.

Weyland, Anita, "Engagment and Talent management of Gen Y", Emerald Group Publishing Limited, 2011, Vol 43 No 7.

Wujanto, Seto Hadi, Structural Equation Modeling dengan Lisrel 8.8, Graha Ilmu; 2008 